\title{
CONSTRUYENDO PODER EN EL ALTO NEUQUÉN: EL RELATO DE UNA MUJER CAMPESINA ${ }^{1}$
}

ROLANDO SILLA*

\section{RESUMEN}

Se pretende hacer una traducción analítica de un conocimiento vernáculo analizando una entrevista realizada durante un trabajo de campo a una mujer campesina del Alto Neuquén. En ella se aprecia la reflexión de la entrevistada sobre sus recuerdos de las migraciones realizadas por sus antecesores desde Chile a la Argentina. Las consecuencias de estos sucesos hacen especial referencia a prácticas e ideas que debieron ser incorporadas a una cultura nacional argentina. Esto se evidencia cuando relata tanto su fidelidad al santo patrono de la localidad como al partido provincial. En relación a estos eventos podemos encontrar una teoría nativa sobre el poder, la política y la religión. Que todo esto salga de una entrevista señala como en el propio diálogo tenido entre la entrevistada y el entrevistador se va construyendo el sentido de los hechos y acontecimientos. Por ello la entrevistada demuestra ser "una socióloga en estado práctico" en dónde "lo real" ya está descrito por ella, o mejor dicho, se describe y se va constituyendo a partir del diálogo.

PALABRAS CLAVES: poder, religión, mediadores, Neuquén.

\section{CONSTRUCTING POWER IN ALTO NEUQUÉN: THE ACCOUNT OF A PEASANT WOMAN}

\begin{abstract}
The analytical translation of vernacular knowledge expressed in an interview of a peasant woman done during fieldwork in Alto Neuquén is presented. In this interview we appreciate the reflection done around her memory of the migrations of her antecessors from Chile to Argentina. The consequences of these events have special reference to practices and ideas that should have been incorporated to an Argentinean national culture. This is evident when she narrates her fidelity to the local saint as much as to the provincial political party. Related to these events, a native theory about power, politics and religion can be found. This marks the way in which facts and events can be constructed in one dialogue. In this

1 Una versión preliminar fue presentada en el IV Congreso Argentino y Latinoamericano de Antropología Rural, Mar del Plata, 2009.

Investigador asistente CONICET-IDES. Aráoz 2838, Ciudad de Buenos Aires, Argentina. rolandojsilla@yahoo.com.br.
\end{abstract}


sense the woman proves to be a "practical sociologist" where the "real" is described and constructed starting from this dialogue.

KEY WORDS: power, religion, mediators, Neuquén.

\section{INTRODUCCIÓN}

En este artículo se pretende hacer una traducción analítica de un conocimiento vernáculo (Coulon,1988:42). Para ello se analiza una entrevista realizada durante el trabajo de campo a una mujer campesina del Alto Neuquén. En ella se aprecia la reflexión de la entrevistada sobre sus recuerdos de las migraciones realizadas por sus antecesores desde Chile a la Argentina. Las consecuencias de estos sucesos hacen especial referencia a prácticas e ideas que debieron ser incorporadas a una cultura nacional argentina, y más específicamente neuquina. Esto se evidencia cuando relata tanto su fidelidad al santo patrono de la localidad como al partido provincial. En relación a estos eventos, también podemos encontrar una teoría nativa sobre el poder, la política y la religión. Que todo salga de una entrevista señala como en el propio diálogo tenido entre la entrevistada y el entrevistador se va construyendo el sentido de los hechos y acontecimientos. Por ello, la entrevistada demuestra tener un sentido sociológico propio, en dónde "lo real" ya está descrito por ella, o mejor dicho, se describe y se va constituyendo a partir del diálogo. Entonces los datos aportados por la entrevistada están construidos en la interrelación con el entrevistador, $e$ indican que las interacciones mantenidas para recoger el material no se pueden separar del propio material (Coulon,1988:92). El relato recrea la vida y acontecimientos ocurridos en la región en relación a quien se lo está contando. Por ende, el relato de la entrevistadora no es independiente de la presencia del entrevistador. Se recrea y constituye en relación a mí y la posición que la entrevistada cree que tengo. Esto no lo convierte en ficticio.

\section{Primer contacto}

El miércoles 13 de enero de 1999 arribé por primera vez a la localidad de Las Ovejas, ubicada en el departamento Minas de la provincia de Neuquén, Argentina. El objetivo era realizar un estudio sobre la fiesta en honor a San Sebastián que se lleva a cabo todos los 20 de enero. Durante esa semana Vicente Palermo, un poblador, me estuvo presentando personas que él consideraba podrían darme buenos datos sobre la fiesta, en especial gente de edad avanzada que suponía habían sido contemporáneos del arribo de la imagen traída desde Chile, hacia la década de 1940. Esto indicaba que el origen y la historia eran, desde su propio punto de vista, un aspecto central del fenómeno. Estaba muy interesado en presentarme a Lucía, pero al mismo tiempo tenía cierto miedo. Cuando íbamos para su casa Vicente me comentaba, medio en broma medio en serio, que no sabía si cuando se encontrara frente a frente con ella lo iba a abrazar o a injuriarlo. Ocurría que si bien habían sido muy buenos amigos, en ese preciso momento estaban enfrentados políticamente. Lucía era del Movimiento Popular Neuquino (MPN). Vicente también era un afiliado al partido, pero estaba en otra línea interna. Lucía era partidaria de Felipe Sapag a nivel provincial y de Alfredo Urrutia, el intendente de la localidad. Vicente por su parte estaba alineado a Jorge Sobisch, un relativamente nuevo referente del partido, si bien ya había sido electo gobernador en 1991. Pero también Vicente, con sólo 28 años de edad, se había largado como candidato a intendente en las próximas elecciones.

Al llegar golpeó las manos tres veces, "así saben que soy de Las Ovejas", me dijo, pero nadie salió. Pensó por un instante que no querían atenderlo, pero finalmente Lucía apareció por una puerta lateral. Se saludaron y Vicente le explicó que yo era de Buenos Aires y que estaba estudiando la cultura del lugar, y que en ese aspecto él la consideraba un referente. También le dio su opinión sobre lo importante que era que desde Buenos Aires se hubiesen enterado de la existencia de la fiesta, y que era un indicador de la centralidad que estaba cobrando el evento. Lucía me contestó que no tenía problema en hablar conmigo pero que en ese momento no podía porque estaba desayunando. Eran aproximadamente las 9 hs de la mañana. Le contesté que no tenía inconveniente en entrevistarla en otra oportunidad. Entonces me dijo que volviera a las 17 hs., y que podríamos hablar hasta 
las 17,30hs. Luego debía ir al santuario, a rezar la novena, o sea, la ejecución de oraciones que se le realizan al santo durante nueve días antes del 20; actividad a cargo de los miembros de la Comisión Procelebración de la Fiesta de San Sebastián, y en especial de las denominadas rezadoras, mujeres reconocidas en la localidad por su conocimiento justamente de las novenas y que acostumbran a cumplir esta función tanto en la celebración de San Sebastián como en otras situaciones como los velorios. Lucía era una de ellas ${ }^{3}$. En ese día yo aprendí lo que era una novena. De haberlo sabido hubiera llegado a Las Ovejas unos días antes.

\section{Lengua y modernización}

Regresé a la casa de Lucía a la hora pactada. Me hizo entrar y le pregunté si podía grabar nuestra conversación. Asintió, y comenzó con un tema que consideró central: el habla. Me dijo que no iba a hablar como moderna[...]porque no podemos, porque si nosotros queremos cambiar la palabra a moderno ahora nos sale mas mal que si hablamos a la costumbre. Le dije que no había problema, que la podría entender de todas maneras.

El tipo de español que se habla en la región es muy diferente al de Buenos Aires, e incluso diferente al que se habla en la ciudad de Neuquén. Un tiempo después, hablando con un criancero, tal cual se denomina a la gente que allí vive en las áreas estrictamente rurales, me estaba contando como perdió gran parte de su ganado en un viento blanco (tal cual como llaman a las tormentas de nieve). Ocurría que mantuvo su ganado muy entrado el otoño en su campo de veranada y lo sorprendió una tormenta. De repente me dijo yo no le hice juicio a mi padre. En principio no comprendí por qué si estábamos hablando de su ganado y una tormenta de nieve la conversación había girado hacia un pleito judicial con su padre. Finalmente me di cuenta de que juicio estaba bien utilizado, pero en una acepción y contexto que no era habitual para mí. El criancero quería decirme que no le había

3 Lucía también fue cantora en su juventud, actividad que también posee gran prestigio. En otras oportunidades me dijo que dejó de cantar porque tuvo un problema en las cuerdas vocales. Pero otras personas decían que el motivo fue por celos, ya que era muy golpeada y maltratada por su marido cada vez que actuaba (Silla,2006). dado la razón, no había hecho caso al consejo de su padre de retirarse unos días antes a las tierras bajas. De ser así hubiera evitado el viento blanco.

Esta diferencia en el tipo de español también trae disputas entre especialistas que viven y operan en la región como los maestros, muchos de los cuales no son originarios de allí y no sólo consideran que los habitantes de la región hablan mal el español, o lo hacen de una forma achilenada, sino que en las escuelas obligan a hablar a los niños de acuerdo a la región de donde cada uno proviene, no necesariamente de Buenos Aires. A este debate generado por personas que no son de la región y con las que los habitantes interactúan, Lucía lo interpretó, al menos ante mí, como ser o no ser moderno, presuponiendo, creo, que por venir de Buenos Aires, o al menos de afuera de la zona, yo sí lo era. Este hecho también evidencia que Lucía considera, al menos en este caso, el impulso hacia lo moderno y la modernización como proveniente de afuera de la región y de su gente. También marca que la forma en que decide hablar es un acto ritual y una afirmación de su status personal (Leach, [1954]1995:111). Podríamos preguntarnos si está manipulando su forma de expresarse tendiendo a identificarse lingüísticamente con aquellos que possen influencia política y económica (Ibid. 112). En su caso, parece colocarse frente a mi como miembro de otra comunidad lingüística, diferente a la que en su propia opinión es "más moderna". Es sabido que para Leach estas son actitudes concientes y pragmáticas. Personalmente no quiero ponerme ni de un lado ni del otro; pues todos los actores sociales podemos actuar algunas veces de forma espontánea y otras midiendo nuestras acciones; máxime en un caso como el descripto, en dónde ambos participamos de una entrevista grabada. Sí me parece evidente que Lucía pudo optar por intentar hablar como yo o pudo decidir hablar como ella lo hace habitualmente; y es evidente que se consideraba con el poder de decidir esto frente a mi. Más allá de que haya sido una forma de manipulación o no, creo importante resaltar que supo que tenía varias posibilidades. No estaba condicionada a hacer lo que hizo, a optar por una sola opción.

\section{El campo y la ciudad}

En esa misma conversación, y antes de hablar sobre el tema específico de nuestra entrevista, que era la fiesta y devoción a San Sebastián, Lucía 
sintió la necesidad de explicarme por qué vivía en el pueblo; pues ella era del campo, pobre y de origen chileno. También pareció marcar una división temporal. Señaló que antes (sin dejar claro cuánta profundidad histórica tiene este antes) todos (sin explicar tampoco quienes eran todos) estaban en esa misma condición. Me explicó que antes todos tenían casitas ranchos, que no había caminos y que no se conocían los automóviles, pues su única motricidad eran los caballos, los mulares o caminar. También me aclaró que ella no era nacida en Chile sino sus abuelos. Lo mismo me dijo de su marido, que también estuvo presente durante la charla, pero sin emitir demasiadas opiniones. Lucía me explicó que debieron mudarse al pueblo cuando sus hijos comenzaron la escuela. Esto ocurrió hacia finales de la década de 1960.

Tengamos en cuenta que en 1963 ganó por primera vez la gobernación de Neuquén Felipe Sapag, al frente del también nuevo MPN. Sapag creó una fuerza política perdurable que incluso desafió a Juan D. Peron, ganándole la pulseada a nivel provincial en las elecciones de 1973 (Palermo,1988:7). Como amasó su fortuna a partir de emprendimientos comerciales en varios pueblos del interior de la provincia, consiguió crear la sensación de que pertenece a una clase alta surgida "por esfuerzo propio y desde abajo". Respecto al partido que contribuyó a fundar, nace de la proscripción al peronismo. Hacia finales de la década de 1950 , los militares y políticos más aperturistas consideraban que dándole espacio a partidos provinciales y simultáneamente proscribir el peronismo a nivel nacional era una manera de disminuir el poder de Peron. En 1963 triunfó Arturo Illia con la Unión Cívica Radical de Pueblo a nivel nacional y el MPN en Neuquén, bajo la candidatura de Felipe Sapag, quién comenzó su gestión de obra pública, alejándose del conflicto peronismo-antiperonismo. Vicente Palermo califica al MPN como neoperonista (tendencia que paulatinamente irá dejando de lado), provincialista (ya que hace del discurso federalista y defensa de los intereses de la provincia frente a Buenos Aires una de sus principales banderas), tecnoburocrático (con una gran inversión en edu-

4 En Neuquén la vivienda se incrementó de 21.889 unidades habitacionales en 1960 a 34466 en 1970, y 59180 en 1980. Los complejos habitacionales crecen a un ritmo superior al de la población (Arias Bucciarelli,1999:51). cación, salud y vivienda ${ }^{4}$ y carismático (Ibid.), en el caso del liderazgo de Felipe Sapag (claramente descrito en este caso por Lucía).

Las Ovejas existe como paraje al menos desde principios del siglo XX, ya que por ejemplo la escuela primaria data de 1907. Oficialmente el aniversario es el 21 de Mayo, fecha en que está firmada el acta de fundación de la Asociación de Fomento, en 1937. Sin embargo se acostumbra agregar en los folletines y actos conmemorativos que es en 1880 cuando comienza el primer caserío de inmigrantes chilenos. Lo interesante del relato de fundación oficial es que posee una estructura típica del relato de fundación de la misma Argentina. Se desconoce la preexistencia de población indígena y se toma como origen de la nación a inmigrantes, en este caso de nacionalidad chilena, cuando en gran parte del país se acostumbra a señalar inmigrantes de diferentes nacionalidades de origen europeo. Otro punto interesante es la fecha exacta de 1880: justo el año en que el ejército argentino invadió la zona y ocupó el territorio sometiendo a indios y poblaciones chilenas (Manara,2008).

Pero en este caso Lucía me contó el origen de la localidad, o al menos su modernización, su transformación en caserio, como una gesta relativamente reciente y propulsada por Felipe Sapag, la familia Urrutia y el MPN. Me explicó que cuando comenzaron las primeras obras el intendente era Raúl Urrutia, y su esposa la directora de la escuela. Describió a Raúl como el único señor que tenía dinero, que podía hacer las cosas. Porque todos los demás éramos pobres. Teníamos animales, pero viste, no vamos a ir a caballo, y no sabíamos viajar. Éramos totalmente atrasados; y bueno, ese señor fue a la gobernación a Neuquén, a golpearle las puertas a Don Felipe Sapag, para que le diera una ayuda para fundar este pueblo. Así empezó. El señor Raúl Urrutia le pidió a Don Felipe Sapag ayuda para este pueblo. Él vino después y vio que era necesario. Y Don Felipe inició. Se hicieron las diez casas primeras, que son unas de las de nosotros. Y bueno, así empezamos, a trabajar juntos, con el señor Urrutia, desde el principio de este pueblo, desde sacar la primera piedra, desde sacar el primer mato, hasta sacar los arbustos. Yo con mi marido y otras personas, algunas viven otras ya han muerto, y la familia Urrutia. Ha fallecido el padre. Siguió trabajando Alfredo, que fue el 
que me ofreció esta casa. Después vinieron otros. Estuvo la señora de él, la que era directora estuvo de intendenta. Después pasaron los años, y vinieron algunos otros intendentes. Después volvieron a retomar ellos mismos, la familia Urrutia. Porque la gente los pide y la gente los vota.

El éxito de una fuerza política provincial depende de que los electores perciban que sus intereses y expectativas relacionadas con cuestiones que se dirimen en el plano local y con cuestiones que se dirimen en relación provincia-nación, pueden ser defendidos por una identidad política autónoma más adecuadamente que por la expresión provincial de un partido nacional (Palermo,1988:11). Así, Lucía señaló a la familia Urrutia, Felipe Sapag y el MPN como agentes por excelencia en el proceso de modernización de la región, algo que los partidos de representación nacional no pudieron hacer. Esto implicó que en un área estrictamente rural ocupadas por campesinos minifundistas se estableciera un pueblo constituido básicamente por lo que en la región se denominan casas de la provincia: viviendas construidas a partir de planes de vivienda otorgados, o cuyos beneficiarios creen otorgados, por el Estado provincial. En algunas ocasiones los planes pertenecen a proyectos y partidas presupuestarias del Estado nacional, pero existen estrategias para que esos planes aparezcan, frente a los destinatarios, como ejecutadas por el Estado provincial, y por ende por el MPN, como una acción de desarrollo autónomo y federal. Como en Neuquén Partido político y Estado son prácticamente una misma cosa, ya que desde que la provincia fuera tal, en 1957, y salvo gobiernos de facto, siempre gobernó el MPN, los planes y acciones que ejecuta el gobierno son sinónimo de acción del partido. Incluso es de notar como el MPN siempre mantuvo algún grado de decisión sobre la provincia, pues los quiebres en el orden constitucional desplazaron al partido del poder pero no lo desarticularon. Sus figuras mas destacadas se mantuvieron en organismos de planificación y próximas al poder, al punto que en 1970 el presidente de facto Onganía nombró a Felipe Sapag como Comisionado Federal (Arias Bucciarelli,1999:41).

Aclaremos también que desde 1884 hasta 1957 Neuquén fue considerado un Territorio nacional, o sea, una entidad jurídica que, a diferencia de las provincias, constituía una mera circunscripción administrativa sobre la que el gobierno central debía ejercer su función de homogeneización económica y social para llegar finalmente a la provincialización (Arias Bucciarelli,1999:32). Hasta 1943, la participación electoral del poblador neuquino se reducía a algunas elecciones municipales. La reforma de 1949 dispuso la posibilidad de elegir presidente en los Territorios Nacionales, y la Ley electoral 14302 acordó que podían elegir un delegado (con voz y sin voto) del Territorio en la Cámara de Diputados de la Nación, así como concejales para los municipios (Palermo,1988:15). Recién en 1957, luego de ser convertida en provincia, los habitantes de Neuquén pudieron elegir gobernador. El acuerdo Frondizi-Peron hará que la Unión Cívica Radical Intransigente gane las elecciones en esa ocasión (González-Scuri,1999:94). Queda claro que el tan promulgado acceso pleno a la ciudadanía política de los argentinos a partir de la Ley Saenz Peña en 1912 y el voto a la mujer en 1947, proclamado por gran parte de las ciencias sociales porteñas, no prestó atención a la falta de derecho político pleno de los habitantes de los Territorios Nacionales hasta mediados del Siglo XX. Según Palermo, esta carencia de ciudadanía política determinará que los procesos de constitución de identidades políticas nacionales (liberalismo en el Siglo XIX, y radicalismo y peronismo en el XX) no tuvieran su expresión local (1988:16).

Volviendo al relato de Lucía, se hace evidente la necesidad de crear un pueblo para traer mejoras. Pareciera que el aumento de la calidad de vida a partir de una existencia estrictamente rural es prácticamente inconcebible. Existe en la región la convicción de que la ciudad es el repositorio de la civilización, y el habitante de la ciudad, como verdadero portador de ésta, comanda al que vive en el campo, por lo tanto, ser un campesino, un criancero, no conlleva ningún prestigio.

El relato también señala un interjuego de jerarquías, entre los que, desde el punto de vista de Lucía, tienen el poder político y económico para decretar que las cosas se hagan, y los pobladores, pobres y viviendo en un plano de igualdad, que colocan el trabajo para que las cosas final y concretamente se hagan. El poder parecería estar previamente distribuido y ella sería de las que ocupan el escalón más bajo. Pero veremos que esto no le impide actuar. 
La gente, Dios y el Movimiento

Bruno Latour ha señalado que se ha hecho común en las ciencias sociales pensar que para lograr objetivos políticos que consideramos deseables para el buen desarrollo de nuestras sociedades (como demostrar la conciencia de las clases populares de la desigualdad en que viven, la asimetría de poder, la preocupación de la población por el mantenimiento y mejoramiento de la democracia, etc.) no necesitamos tanto inventariar las fuerzas activas que nuestros sujetos de estudio consideran existen en el mundo como eliminar las muchas que, a los ojos de los investigadores, atestan el mundo y mantienen a las personas en estado de alienación. Esta tarea de emancipación implica que disminuyamos, ocultemos o neguemos, la cantidad de agentes activos aceptables (2008:77). Al limitar los agentes perdemos la capacidad de objetivar la vida social tal cual sucede, alejándonos de las pretensiones de descripción y explicación empírica de las cuales participan las ciencias sociales; y tal vez también esto nos impida realizar buenos diagnósticos de lo que ocurre en la vida social. Trataremos, por ende, de seguir la trayectoria y los vínculos de todos los agentes involucrados en el relato de Lucía.

Lucía pasó de referirse a Felipe Sapag y la familia Urrutia a hablar de su propia trayectoria política, en especial su primer cargo de concejal y la posibilidad de volver a ser elegida: me eligió la gente. Me llamó. Me pidió que me anotara para concejal. Esto fue en 1983. Sabido es que la generalidad y ambigüedad de la expresión la gente produce un sentido de totalidad y homogeneidad. Hace creer que toda la población (sin importar clase, etnia, sexo u edad) quería que ella los representase. Sin embargo Lucía manifestó que en realidad no quería, no tenía interés en ser concejal. Por ello alguien pidió que la colocaran por lo menos en el último lugar de la lista, como homenaje. Porque todos los días ando, andaba haciendo algo por el pueblo, para alguien. Porque vivo con la gente. Vivo siempre con la gente. Si hay un enfermo, ahí estoy yo con ese enfermo, para ayudarle. Si hay un velorio, ahí en esos mayores dolores de la gente estoy yo con ellos, con una palabra persuasiva o rezando, porque me gusta rezar, rezar por las almas. Si alguien tiene un chico enfermo, voy se lo curo. Porque curo el ojo.
Hacer cosas por la gente no sólo implica el acto de dar bienes materiales a las personas, sino acciones como curar el mal del ojo o rezar por otros.

Lucía no se consideraba completamente responsable de haber sido elegida concejal. Primero porque la eligió la gente y ese alguien que la quiso, fuese como fuese, colocar en la lista. Pero también porque cuando (la lista) llego a la mesa electoral, la vio Felipe, y dice no, esta señora no puede estar acá. Porque yo toda la vida he sido del partido, del movimiento, y empecé a trabajar en este pueblo, con esta gente empecé a trabajar, y antes no ejercía ningún otro partido, y era nomás que el movimiento. Bueno y seguimos con mi marido porque todo lo hemos hecho junto con él, y trabajando en el partido; y (Don Felipe) nos conoce por supuesto, porque siempre viene acá. Dice, esta señora no puede estar en el último renglón. La vamos a poner en el tercer lugar, y me pusieron en el tercer lugar.

Una vez elegida "por el pueblo" para que lo represente, fue elegida por el que ella considera el máximo representante del partido para que lo defienda. Esto fue una acción directa, ya que Lucía señala que Don Felipe los conoce, conoce a su familia y su actividad en Las Ovejas y la Zona Norte. Se ha considerado el liderazgo de Felipe Sapag como poco mediado por los medios (Palermo, 1988:35) y gran parte de su prestigio implicaba su capacidad de al menos hacer creer que conocía y se preocupaba personalmente de todos los neuquinos. Lucía señala cómo Felipe los conocía, y es común escuchar a muchos pobladores decir lo mismo ${ }^{5}$.

Por último, Lucía me dijo que su cargo se lo debe a Dios:

sabes que yo tengo tanta fe en Dios, yo digo Dios me quiso poner ahí. Dios me dio ese puesto, porque yo no lo quería. Nunca quise y nunca lo pensé que podría llegar a primer lugar de concejal, $y$ estoy tranquila trabajando.

\footnotetext{
5 Felipe Sapag era tan conocido, y su liderazgo tan natural, que Palermo cuenta una anécdota que también escuché durante nuestro trabajo de campo: "en pleno Proceso de Reorganización Nacional unos periodistas, buscando al Gobernador interino Gral. Trimarco en una localidad de la provincia para cubrir un acto de inauguración de una obra pública, preguntaron a unos pobladores rurales si por ahí no había pasado el Gobernador. La respuesta fue: no, don Felipe por aquí no pasó" (1988:106).
} 
Desde el punto de vista de Lucía, tenemos varios agentes por los cuales llegó a esa instancia de poder. Perteneció al partido desde sus orígenes y siempre mantuvo la lealtad a Felipe Sapag. Dos características que Vicente no tenía, porque era muy joven para haber estado desde el comienzo y porque se pasó a otra línea interna. También considera que trabaja para la gente y esto es una razón para considerarla una posible candidata. Ayudar a la gente significa cosas muy variadas y de relación cara a cara: visitar enfermos, asistir a velorios o curar el ojo.

Por otro lado tenemos tres agentes que hicieron posible, según Lucía, que su cargo se efectúe. El primero es esa persona de la localidad y del partido que dijo que ella debería estar en la lista. El segundo es el propio Felipe Sapag, que la confirmó, y el tercero es un agente no-humano: Dios. Que una campesina, que como ella misma dice, "no estaba preparada" llegue a ser electa concejal refiere a una especie de milagro. Si bien no lo designó con este nombre, las peripecias para llegar a integrar la lista y luego ganar parecen haber sido, tal cual lo relata, cierto misterio o destino diseñado por Dios. En este caso, Dios aparece como un no-humano que genera cosas. Desde no querer participar hasta ocupar un puesto en dónde con seguridad iba a entrar como concejal. Si seguimos el relato de Lucía, Dios no es la sublimación de la sociedad o el poder o la Iglesia Católica. Cuando habla de gente preparada se refiere a los Urrutia, cuando habla de personas con poder se refiere a Felipe Sapag, cuando habla de la "sociedad" se refiere a la gente, cuando habla de Dios y su fe en él no está haciendo ninguna metáfora ni ocultando nada; ni siquiera se está refiriendo a la Iglesia Católica como institución. Se refiere a un ser superior que se supone tiene poderes también superiores a los humanos. Podríamos ocultar este factor y dar una explicación política y sociológica al discurso de Lucía, pero preferimos abandonar la idea de que todos los lenguajes son traducibles al idioma ya establecido de lo social (Latour,2008:67). Si Lucía no sublima, si no cree en Dios y su poder, sino que posee la certeza de que Dios existe y tiene poder, al igual que tiene la certeza de que, si bien en otro plano de existencia, las familias Sapag y Urrutia existen y tienen poder, entonces Urrutia, Sapag y Dios son mediadores que permiten la acción y la transformación. Cuando me refiero a este último término lo estoy haciendo en el sentido que le da Latour: si un intermediario es algo que transporta significado o fuerza sin transformación, por el contrario, un mediador es algo que tiene una especificidad tal que debe tomarse en cuenta cada vez; que transforma, traduce, distorsiona y modifica el significado o los elementos que se supone deben transportar (2008:63). Así Lucía distingue entre humanos y no-humanos, y a cada uno le otorga diferentes jerarquías y cuotas de poder. Podríamos utilizar la clásica metáfora de los actores sociales como marionetas, y a Lucía misma como una marioneta. Ella es activada por todos estos agentes, por todos los hilos de los cuales además es conciente y capaz de reflexionar y emitir teorías al respecto. Pero el poder político y el poder divino no aparecen aquí como mecánicos, ni como dominación, pese a que podríamos considerarla una integrante de las clases subalternas. El poder y los que lo detentan no aparecen como intermediarios, no transportan la dominación desde ellos hacia Lucía. Más bien aparecen justamente como mediadores. Todos actúan sobre ella, pero en vez de limitarla le permiten, le facilitan la actuación. El poder de estos agentes y sus decisiones son transformadas por Lucía, que a su vez hace muchas cosas: trabajar para construir sus casas, para crear el pueblo, ayudando a los vecinos, actuando como curadora, etc.

La actitud natural encierra una capacidad para tratar los objetos, las acciones y los acontecimientos de la vida social con vistas a conservar un mundo común. Por ello el mundo está ya descrito por los miembros (Coulon,1988:16). Esta descripción no tiene por qué coincidir con las que da el científico social. Entonces no consideramos correcto rechazar la explicación de los actores, pues, tal cual lo ha señalado Harold Garfinkel, si el problema del conocimiento y método que utilizan los actores queda marginado, los actores son tratados simplemente como "idiotas que juzgan"([1968]2006:82). Es arbitrario imponer el conocimiento científico como estándar con el que evaluar los juicios de los actores. Si entonces dejamos a un lado las concepciones ideales de la acción racional, queda abierto el camino para iniciar investigaciones basadas en las propiedades del conocimiento que el actor aplica realmente al efectuar elecciones razonables entre alternativas de acción, o sea, las operaciones de juzgar, elegir, valorar, etc., 
que emplea de hecho (Heritage, [1987]1995:298). Si teniendo en cuenta lo dicho seguimos el relato y las vinculaciones realizadas por Lucía al explicar los acontecimientos, vemos que posee toda una teoría de la acción social; de mediadores que hacen que otros mediadores hagan cosas (Latour,2008:308). Por ello cuando más enlaces tiene Lucía, cuando más hilos la manejan (como Urrutia, Sapag, el MPN o Dios) más existe, más realiza. El poder de los otros no es percibido como algo negativo para ella, no es algo de lo que haya que liberarse. El poder de los agentes con los que ella interactúa la dotan de poder. Tenemos, entonces, una teoría nativa del poder, de los poderosos y de sus implicancias.

Digresión sobre el mal del ojo

En otra oportunidad Lucía me contó que una mujer le enseñó a curar el ojo, cuando ya las doctoras no pueden, no le encuentran nada a los chicos, le dicen llévenlo a lo Lucía. Los traen y yo los curo. No les doy nada de tomar y los curo con oraciones, con tanta fe, esa fe que tiene uno en Dios y la Virgen; y les digo, no soy yo la que curo. Yo hago la obra, porque quien cura son Dios y la Virgen. Ellos son quienes curan a los niños. Vienen con sus niñitos, ya que le dicen que no tienen nada en el hospital; y no tendrán nada, porque yo los curo y los nenes se duermen, y cuando se levantan se levantan contentitos. Les hago 3 curaciones $y$ los nenes se sanan.

¿Siempre son los niños o una persona grande también puede enfermar?

También se saben ojear las personas grandes

¿Y como uno sabe si está ojeado?

Le duele mucho la cabeza, y por más que vos te des calmante no se te pasa el dolor de cabeza, y la vista. Eso es lo que dicen. Nunca he estado ojeada. Eso es lo que me han dicho las personas que he curado.

¿Y por qué se produce?

Según lo que yo he leído, y lo que he visto, se produce según el signo de la persona, tienen una vista muy fuerte, por la sangre que tiene, esa sangre fuerte, y la vista. Al mirarla fijo se ojea. Al mirar fijo y decirle que bonito por ejemplo. Un yerno mío fue un día a Chos Malal (la ciudad más grande de la zona), y fue a una fiesta. Se le acercaron dos chicas. Lo miraron fijo y le dijeron que lindos ojos tenés, le dijeron que lindos ojos tenés, churro. Las chicas se fueron y se le puso un dolor de cabeza que no se curó hasta que lo cure yo. Así creo que debe ser.

Mi madre cura la ojeadura

Aja...

No sé si la cura igual que usted. Ella pone en un plato agua y tira aceite con una cuchilla, y dice algo. No sé lo que dice

No, yo no curo así. Yo acuesto al nene. Traigo una vela prendida, un crucifijo y con ese crucifijo lo santiguo en la frente, le hago la oración de la curación y ya está; y se lo ofrezco a Dios y la Virgen, que cure el niño. Así curo.

No mantener una postura neutral, sino iniciar un diálogo con ella, en dónde ambos hablamos sobre lo que sabemos de un tema determinado, le permite explicitar su propio saber. Pero también le estoy señalando que puedo también no ser moderno.

Por su parte Vicente, su contrincante político, también curaba el ojo. Cuando le pregunté dónde aprendió se echó a reír y me dijo que a través de Predicciones, una revista publicada en Buenos $\mathrm{Ai}$ res dedicada a "lo oculto", poniendo así en duda la habitual relación que los antropólogos tenemos de asociar lo tradicional a lo local. Según me contó, en Las Ovejas solo sabían curar este mal un hombre que ya estaba muy enfermo y abandonó, y Lucía que cobraba hasta $\$ 5$ por sesión (en esa época $\$ 1=$ u\$u 1), y se debía ir a tres sesiones. Entonces él comenzó a curar gratis; y con éxito. Dice que incluso en algunos niños consiguió que su cura dure hasta 8 meses. Vicente también le daba importancia a la fe, pero a diferencia de Lucía, hacía hincapié en la fe o no que se le tiene al curador.

Nuevamente podríamos pensar que curar el ojo es una forma meramente pragmática para obtener más votos engañando a la población. Claude LeviStrauss ya señaló en su clásico "El Hechicero y su magia" que la eficacia en la magia implica la creencia en la magia y presenta tres aspectos complementarios: a) la creencia del hechicero en la eficacia de sus técnicas; b) la creencia del enfermo o víctima; c) la creencia de la opinión colectiva en el mago y sus técnicas ([1958]1997:196). De todas maneras, al señalar un caso de un shaman escéptico pero que también curaba, es evidente que Levi-Strauss coloca, afín a Durkheim y Mauss, el foco central en la creencia colectiva. Creo que en nuestro caso se hace 
evidente que tanto Lucía como Vicente consideran que el mal de ojo realmente existe y que puede $y$ debe ser curado, que más que una creencia, tal cual la señala Levi-Strauss, es una certeza, y que curarlo es un saber. Que esto sea visto como una virtud, y que esta virtud "se trasforme", por así decirlo, en poder político, solo convierte a el saber de diagnosticar y curar en un mediador más, susceptible de múltiples aplicaciones y potencialidades, una de ellas política y fuente potencial de poder.

\section{El sacrificio}

¿Por qué si fui y pacté con Lucía una entrevista para que me contara su visión de San Sebastián y la fiesta que se celebra en su nombre, me habló todo el tiempo de su fidelidad incondicional al MPN, la familia Urrutia y Felipe Sapag? Era evidente que Lucía quería marcarme la diferencia que existía con quien yo me había presentado: Vicente, su opositor político, pero también su gran amigo. Como uno de mis objetivos, y más en estas primeras aproximaciones de mi campo, era intentar obtener categorías que me permitieran dar cuenta del modo en que los informantes concebían y vivenciaban una situación, continué con la técnica de atención flotante: escuchar sin privilegiar de antemano ningún punto del discurso (Guber,1991:215). Por ello, si bien tenía sólo media hora para hablar sobre San Sebastián, continué con la línea de conversación que Lucía consideraba indispensable explicarme, y que en principio no era religiosa sino política. Entonces pregunté:

¿Y usted siempre fue del movimiento?

Siempre, toda la vida, fui y voy a ser siempre. Porque ese es mi trabajo, o sea, el trabajo de nosotros; y nosotros no podemos ahora entregar nuestro trabajo a otro partido, porque lo que hay lo hemos hecho con el partido, el MPN y con Don Felipe Sapag; y empezamos de la nada como se dice, de sacar la primera piedra, el primer monte, y cuando era todo difícil. En ese tiempo estaban solamente los camiones de Gendarmería. Porque no había camino. Todavía no estaba el puente. Pasaban en una balsa y ahí pasaban los vehículos; y empezamos con mucho sacrificio. Porque como ya te digo, en donde no hay nada como no va a haber sacrificio. Entonces es nuestro trabajo, con los señores Urrutia y con toda la gente que había de antes. Todos pusimos un grano de arena para hacer, y ahora no podemos dejar que venga otro partido a quitar lo que nosotros hemos hecho. Ahora vienen varios partidos, ¿por qué no vinieron cuando era difícil? Hubieran venido antes, hubieran ganado ellos, y no solo el pueblo de Las Ovejas, todo el norte neuquino, esta hecho, vamos a decir, por Don Felipe Sapag. Porque ahora, hasta en los últimos rincones del país hay una escuela, a donde flamea una bandera argentina. Hecho por Don Felipe, toda la zona norte. Te hablo de la zona norte porque es lo único que conozco. El departamento de Minas, todo ayudó Don Felipe. Si algunas personas se olvidan, no les gusta, no se la idea de ellos, pero nosotros no, nosotros hicimos las cosas. Con el señor Urrutia, que fueron los que empezaron, y con toda la gente que vivía acá. Toda gente dispersa, pero ya empezamos todos a ayudar. Por allá unos viejitos que todavía viven los dos que se llaman Don Domingo Lavena y Doña María Bravo, esos viejitos empezaron. El señor con un hijo mayor hacía los bloques y la señora hacia el pan para los trabajadores en un horno de barro. Cuando en aquellos tiempos, en verano, esta señora llegaba transpirada; y entonces lo hicimos con el sudor de la frente, como se dice a la antigua. Este pueblo y todo lo que hay, y lo queremos como de nosotros. Es una cosa íntima, una cosa de nosotros, y no podemos entregárselo a otro ahora. ¿Vos crees que yo tengo razón en esto?

Al describir una acción cotidiana, la finalidad tal vez no debería estar tanto en explicar la escena sino en mostrar como el mundo es fabricado (Coulon,1988:49). Lucía va construyendo un relato en dónde negar el actual poder político es negar casi todo lo creado. De esta manera construye realidad en el relato. Por lo que ella piensa y experimentó en su vida, y por contar la historia de una forma y en relación a con quien está hablando. En este caso no quería dar mi opinión. De todas maneras le dije que me parecía bien lo que decía, si a ella eso le parecía correcto. La pregunta no es gratuita. Es claro que el relato refiere indirectamente a Vicente cuando habla de los que olvidan el sacrificio hecho por los pobladores "ayudados" por el Movimiento creado por Sapag. Cuando otros partidos políticos no tenían llegada a la región, y tampoco existían líneas internas dentro del MPN. 
También el nexo con la tradición bíblica es muy claro cuando refiere a la obra de construir el pueblo con el sudor de la frente, clara metáfora inscrita en el Génesis, en dónde trabajo implica sufrimiento y es un hecho constitutivo de la humanidad después de la caída. Por ello sacrificio remite a una "cultura bíblica”: las historias del texto bíblico servirían como referencia para pensar las experiencias vividas actualmente (Velho,1995:16). Así, los traidores (en rigor otra categoría bíblica) se olvidan del sacrificio realizado; y tal vez ni si quiera lo recuerden, ya que eran muy jóvenes o no habían nacido cuando ello ocurrió. Pero además los traidores rompen con ese toda la gente, pues ya no son un grupo en dónde todos son iguales en la pobreza, y sólo hay una familia "preparada" para ayudarlos. Ahora los propios pobladores están divididos por diferentes partidos y líneas internas dentro de este. Esto conforma un tipo de asociación diferente al que antes conocían. Lucía entonces señala que últimamente está apareciendo un nuevo tipo de asociación, diferente al que ella vivió en el pasado. Esto tiene para ella un valor ambivalente, porque por un lado estos cambios produjeron una mejora en su forma de vida (mejores casas, mejores caminos, etc.) pero también trajeron la disociación de un grupo humano que, al menos en su recuerdo, o como ella quiere recordarlo, estaba unido. Innovaciones como la educación media hicieron aparecer personas y grupos que también se consideraron "preparados" para disputar cargos de liderazgo, como en el caso de Vicente. Por otro lado, también soy yo interrogado por ser de afuera, al igual que esos otros partidos que llegaron cuando ya estaba todo realizado. Haber construido un pueblo, haber hecho una escuela en dónde flamea una bandera argentina no es sólo un acto de gobierno o acción de partido. Es claramente una forma de argentinizar, de crear una nación y una conciencia y sentimiento nacional, y por ende un tipo diferente de colectivo.

Las Ovejas es un municipio que cuenta con una importante cantidad de servicios en relación a la distancia geográfica que tiene con los principales centros urbanos de la provincia y el país: Juzgado de Paz, Comisaría, Correo, escuela primaria y media, hospital de nivel III (internación sin quirófano ni especialistas), tendido eléctrico, gas, agua corriente y red cloacal, radios FM y televisión por cable. Contaba (a diciembre de 1998) con 1.153 habitantes; y sobre un total de 260 familias (matrimonios con hijos que viven bajo un mismo techo), 158 declararon sueldos, dando esto un promedio de ingresos de $\$ 596,28^{6}$.

Se considera a la mayor parte de los crianceros dentro de la categoría de pobres rurales, pues utilizan baja tecnología, insuficiente inversión de capital y limitada intensificación. Por ende, la modalidad de producción trashumante, característica de esta zona, no se correlaciona con el nivel de vida que la mayoría de estos pobladores mantenía al momento de mi estadía. La solución de esta encrucijada entre la media de los ingresos declarados y el tipo de producción considerado siempre en crisis estaba en el alto nivel de empleo público y las transferencias formales a través de políticas de cobertura educativa, salud y vivienda, que homogenizaba la calidad de vida. Si en Las Ovejas sumábamos la cantidad de empleados municipales y provinciales, los pensionados, la planta estable de Vialidad, Gendarmería, la Corporación Forestal Neuquina (sociedad anónima forestal de la cual el Estado neuquino participa), organismos todos radicados en la localidad, sumaban 234 personas, sobre un total de 260 hogares $^{7}$. En promedio casi todas las familias percibían al menos un salario del Estado nacional, provincial o municipal. Esta situación hacía que en un período caracterizado por un alto índice de exclusión social, como fue la década de 1990 en Argentina, esta población en particular estuviera protegida bajo la forma de redes de intercambio personal basadas en relaciones de amistad, parentesco o fidelidad al líder político. Las Ovejas estaba subvencionada por el Estado provincial bajo la forma empleo público. Como el propio Estado provincial está íntimamente ligado al MPN, gestión de gobierno y gestión partidaria se confunden, y es prácticamente un prerrequisito que para obtener un beneficio del Estado provincial se muestre antes fidelidad al partido, acción claramente demostrada

6 Los datos censales fueron obtenidos del hospital de Las Ovejas. El procesamiento es propio. Aquí todavía $\mathrm{US} \$ 1=\$ 1$.

7 Estas cifras se obtuvieron en base al padrón del Instituto de Seguridad Social de Neuquén. Todo empleado de la provincia o del municipio debe estar afiliado a dicho instituto, de allí derivé la cantidad de empleados públicos provinciales y municipales. Los únicos empleados nacionales son los de Gendarmería, cifra que me la otorgaron en el mismo destacamento, y que al momento sumaban 8 personas. Quedan afuera del cálculo empleados temporarios que la Corporación Forestal Neuquina contrata. 
por Lucía. Pero ella no ve en esto último un problema, una traba al desarrollo, sino una potencialidad.

\section{San Sebastián de Las Ovejas}

Sólo al finalizar la primera entrevista Lucía se refirió a San Sebastián y la fiesta en su honor. Comenzó, al igual que para contarme sobre el pueblo, por el origen. Me explicó que no había sacerdote en la región. Que sólo de vez en cuando venía alguno de Mendoza y que no había dónde, no había un lugar donde diera misa, por ello oficiaba en cualquier casa familiar. Entonces me explicó que su abuelo, hacia 1940 comenzó a realizar una colecta y todos colaboraban con lo que fuera. De esta manera se hizo una capillita de paja, barro $y$ techo de carrizo. Bien precario, como era todo acá, en la época en que Neuquén era un Territorio Nacional, cuando nadie daba nada para acá, cuando todavía no existía el MPN.

Entonces pidieron que viniera un sacerdote con más asiduidad, algo que ocurrió. Este empezó a decir que había que poner un santo de patrono. Lucía coloca la agencia de traer la estatua de San Sebastián desde Yumbel a una familia mapuche y muy católicos (...) personas que eran capaces. Tenían mucha plata, muchos animales, vivían allá arriba. Ese señor iba a Yumbel, a lomo de mula iban a Chile. Le fue a pagar una promesa (al santo en) Yumbel y compró un santo para traer. Pidió que se lo traigan en vehículo hasta San Fabián. Desde allí le pagó a otro señor que tenía mula, que se llamaba Juan Méndez y Rubén Rodríguez.

Así el santo fue llevado desde Chile a Las Ovejas ${ }^{8}$ por una familia que poseía dos atributos en principio incompatibles: católicos y mapuches. Pero además tenían otra cualidad que en general no se atribuye a las poblaciones indígenas sometidas por el

8 Históricamente la población mantuvo fuertes lazos culturales, parentales y comerciales con Chile. Neuquén proveía carnes y derivados, y de Chile se obtenían productos agrícolas. Hacia 1940 Gendarmería Nacional, institución dependiente del Estado nacional fundada en 1938 con la función de vigilar las fronteras internacionales de Argentina, comenzó a operar cortando los pasos. Los habitantes del norte neuquino ya no pudieron comerciar con sus vecinos (y parientes) transcordilleranos, salvo a través del contrabando, quedándoles a sus pobladores como alternativa emigrar hacia la zona centro de la provincia, a ciudades como Zapala, Cutral-Có o Neuquén (Silla,2003).
Estado argentino: tenían mucho dinero y animales. Según Lucía, una vez que se colocó la estatua en la capilla comenzó a venir un cura que se llamaba Pío Gardin. Bueno y así empezó el santo cuando ya lo trajo, ya se empezó a hacer el 20 de enero la fiesta. Toda la gente venía a caballo con sus mulares, con sus chivitos y hacían el asado para todos. Se cantaba, se bailaba con la gente de la zona. No venía gente de otros lados, porque todavía no había camino, no había pueblo. Después ya se hizo el camino, y cuando ya se hizo el camino, vino primero un monseñor, un obispo de Mendoza, que se llamaba Francisco María Buteler. Vino unos años acá, a Las Ovejas, y ahí íbamos y hacíamos la fiesta. Después, cuando ya estuvo el obispo Jaime de Nevares en Neuquén entonces ya vino todos los años. Venía Felipe Sapag.

¿Venia Felipe a la fiesta?

Claro, venía la comitiva. Traía al Ejército, la banda del Ejército para festejar, y traía muchos fuegos artificiales. La capilla todavía era de paja y barro. Después ya todo se fue arreglando y la hicieron nueva, y todos los años que vino el padre De Nevares hacia la velación y después íbamos al calvario, y él echaba las manos al cielo y miraba y le pedía a Dios ayuda para esta zona, y juntamente con Don Felipe Sapag él pedía, y Felipe decía sí lo vamos a hacer, y entre medio de Dios y San Sebastián; y eso fue todo lo que logramos por intermedio de Dios y la Virgen y San Sebastián y todas las prédicas del obispo logramos hacer todo lo que hay acá. Con la ayuda de Dios y la Virgen y San Sebastián, nuestro patrono. Porque sin Dios y la Virgen no hay nada. La fe es muy grande en el santo.

Los sacerdotes impulsaron la capilla, los pobladores trajeron un santo que obligó a los sacerdotes a dar otro impulso a la fiesta para que finalmente la popularidad de la misma fiesta obligue a que ciertas autoridades políticas y eclesiásticas de la provincia asistan y lleguen a la localidad todos los años. Cada acción genera otra y la retroalimenta. Finalmente, los actores son ligeramente superados por aquello que inventaron (Latour [1996]2002:45): la fiesta, el santuario de Las Ovejas y el culto a San Sebastián cobran impulso propio, del cual ya nadie (ni los pobladores, ni los sacerdotes, ni los políticos) se puede atribuir ser el único agente, ser un actor privilegiado del evento. También el santo, en la perspectiva de Lucía, 
es también un agente impulsor de la modernización de la región, así como de la llegada de los elementos de la nación argentina (las bandas del ejército, la comitiva gubernamental, etc.). En la concepción de Lucía, la fiesta en esos primeros años era un ritual que aglutinaba en un sentido durkheimniano a los pobladores y los conectaba con las autoridades eclesiásticas y políticas del ámbito Territoriano primero y provincial después. También desde esta perspectiva, el Estado y la Iglesia, más que avanzando desde el centro a la periferia e imponiendo sus lógicas, aparecen como si fueran traídos y atraídos hacia la periferia por el accionar de los pobladores. Si el Estado y la religión como instituciones son vistas a menudo como agentes de poder que imponen sus prácticas y sentidos, vemos que en la percepción de esta pobladora pareciera que estas instituciones y sus agentes son seducidos por ellos. Casi obligados a ir hacia la periferia. Por ello, y si como intentamos en este trabajo, examinamos la idea y acción de poder tal como es fenomenológicamente captada y ejercida por los actores sociales (Miller,1977:307), en este caso por Lucía, vemos que el poder aquí está repartido en diferentes agentes, cada uno produciendo diferentes acciones. Si en vez de explicar todos estos fenómenos por el poder consideramos que es justamente el poder lo que hay que explicar; si concebimos al poder como el resultado final de un proceso y no una reserva, un stock o un capital que automáticamente proveerá una explicación (Latour,2008:96), vemos que Lucía concibe muchos tipos de poder, así como muchas intensidades de este. Así, el poder político y económico proviene de instituciones y personas de afuera de la región, en especial de Buenos Aires y la capital neuquina. Las Ovejas, por su parte, posee un santuario y un santo que tiene su propio poder, cuyo origen no es el territorio argentino sino un santuario chileno. Pero al mismo tiempo los pobladores, ayudados por agentes no-humanos como Dios y los santos, tendrían cierto poder de atraer a las autoridades políticas y eclesiales; de exigirles que lleven bienes y saberes de sus centros de poder.

\section{Sobre el poder}

Pero, ¿por qué de semejante gesta? ¿Por qué tanto esfuerzo en levantar una capilla e importar un santo patrono? ¿Por qué tanta preocupación en for- talecer la relación entre los pobladores (humanos) y un objeto de yeso no-humano (como lo es la imagen de San Sebastián). Vimos que Lucía dice que fue recomendación de los sacerdotes, y que finalmente el santo ayudó de alguna manera a la modernización, relato muy acorde a los postulados que señalan que en Latinoamérica la modernidad y el proceso de modernización se realizaron de la mano de la fe católica. Pero Lucía no refiere solamente a un problema estrictamente sociológico o a una cuestión de Estado, sino a la fe y la convicción del poder que esos seres tienen, pues le atribuye capacidad de acción, capacidad de mediar, de transformar lo que existe, lo dado:

Nosotros, por ejemplo, que vos querés saber como lo vivimos al santo, lo vivimos con mucha fe. Nosotros vemos que él hace milagros, nosotros vemos que lo que uno con fe le pide se lo acepta, se lo hace, lo tiene. Porque vos sabes que cuando veo en la tele, en Buenos Aires, por lo general, cuando a las madres le roban los hijos. Esas mujeres tan desesperadas buscando a sus hijos. Siempre pienso como pudiera alcanzarle a decir a esas madres que le supliquen a San Sebastián, porque es el descubridor de las prendas extraviadas (...) Porque San Sebastián está en el cielo, no está en Las Ovejas. Él está en todas partes, en todo el mundo. Porque es como Dios, que está en el cielo. Acá en Las Ovejas tenemos la imagen porque le tenemos mucha fe.

La gesta entonces no es gratuita. El santo tiene capacidad de actuar sobre el mundo y las personas. De eso todos ellos están convencidos, pues ven que él hace milagros. Aprovechando quien la está escuchando, y a que en esos días había aparecido por televisión la información de que un niño en Buenos Aires había desaparecido, Lucía apela a utilizarme como mensajero. Tal vez para ampliar el área de influencia del santo, que está en la localidad pero que extiende su agencia a todos lados. Quiso tomarme también como a un mediador, que llevaría, que traduciría, su mensaje en Buenos Aires.

\section{Poder terrenal y poder celestial}

$$
\begin{aligned}
& \text { ¿Usted sabe de la historia de San Sebastián?¿ } \\
& \text { Quien fue? } \\
& \text { Si, fue un soldado romano que nació en } \\
& \text { Milán. Los padres fueron cristianos, y él soldado }
\end{aligned}
$$


romano. El emperador romano era increyente, no le gustaban los cristianos, no quería a los cristianos. Él quería ser él el que mandaba. No creía que había un Dios que mandaba. Era como el rey Herodes. A todos los que eran cristianos los ponía presos o los obligaba que dejaran, que no amaran a Dios. El que no amaba a Dios era su consabido, su querido, su soldado. El que amaba a Dios él lo mataba. Por eso mandó a matar a Sebastián. Primero, cuando se dio cuenta que era cristiano, le preguntó si era cristiano. Era el mejor soldado de Roma, el soldado más querido del emperador. Cuando se enteró que era cristiano, hechó en cara su cobardía de decir que no quería que fuera cristiano, que si quería ser soldado de él, que tenía que ser increyente, no ser cristiano, no amarlo a Dios. Amarlo a él, al emperador. Sebastián le dijo que él tenia fe en Dios, que él creía en Dios y que él era cristiano e iba a ser cristiano siempre. (Entonces el emperador) le dijo que le iba a mandar a matar. Lo mandó a apalear y lo tiraron a un baldío. San Sebastián no murió. Quedó medio vivo y no murió. Una señora, una viuda, lo encontró y lo trasladó secretamente a su casa y lo curó. Cuando estuvo curado le pedían los cristianos que no se presentara ante el emperador. Pero él fue y se presentó. Cuando lo reconoció el emperador lo volvió a llamar, si quería renunciar a la religión para que lo amara a él y que él lo seguía teniendo en el lugar en donde lo tenía. Sebastián no, siguió a Cristo, porque tenía mucha fe en Cristo. Por eso lo ató en un árbol y lo mandó a aflechar por los soldados. Así es que fue muerto por el emperador romano. Porque tuvo mucha fe en Cristo y él prefirió la muerte y no renunciar. (La nieta trae una imagen que ella le había pedido). Ahí está, está atado en un árbol, y con la flecha, donde lo flecharon, y después a palo lo hicieron morir bien, o sea, la primer vez lo apalearon y lo tiraron, a un lugar baldío e inmundo, decía en la historia, bueno y después lo ataron ya lo aflecharon y después lo dejaron

Yahí murió

En la fe

Y a partir de ahí es milagroso

Y a partir de ahí sí, claro. Porque él amaba a los presos que había en ese tiempo. Iba y los animaba que no importaba que los mataran, que no perdieran la fe. Porque acá en este mundo uno vive una pasadita, y en la eternidad es lo que uno tiene que cuidar para que sea una eternidad feliz. Porque mil años delante de Dios son como el día de ayer, y un día en el infierno, por uno renegar la fe a Cristo es como mil años. Entonces tenemos que creer y pensar que tenemos un alma para salvar, que nosotros no somos como los animales que se mueren se pudren y listo. Nosotros tenemos alma, tenemos la señal de Cristo. Cristo nos dio la señal de él porque nosotros somos semejantes a él y tenemos que intentar salvar el alma, y eso es lo que hizo San Sebastián. Por tanto que sufrió se hizo mártir, no ve que se dice noble mártir San Sebastián. Dios le dio el poder para que cure enfermos, para que la ayuda que uno le pide él la conceda (...)

Y usted que piensa, ¿toda persona que muere sufriendo y con fe puede ser milagrosa?

Puede ser milagrosa porque sufre. Entonces Dios lo tiene en su reino, y si uno le pide a esa persona esa persona le pide a Dios, porque está con él.

El sacrificio que Sebastián hizo por Dios, entregándole la vida, le otorgó un poder eterno, entregado por Dios. Entonces Sebastián debió optar entre el poder terrenal (finito) del emperador o el de Dios (eterno). El sacrificio, el sufrimiento y el jugarse por una causa convirtió en mártir a Sebastián; y esto es una manera de obtener poder.

Sin embargo, el relato de San Sebastián no es una simple réplica de la vida de Lucía y su experiencia con el poder político y económico local y provincial. En este último relato el poder terrenal es claramente diferente al poder celestial. Por ello no podemos decir que existe representación. Al comienzo de la entrevista Lucía refirió el poder de Dios y San Sebastián como contribuidor de la continuación del poder político y económico de la familia Urrutia, Felipe Sapag y el MPN. Pero cuando Lucía refirió a la historia de San Sebastián, en el más claro estilo bíblico, narró una contraposición entre el poder terrenal y el celestial. En su relato aparece, ante la soberbia del emperador, el misterio de la gracia otorgada por Dios, cuya esencia es que no respeta el orden de los hombres, el orden social (Peristiany/Pitt-Rivers,1993:25; Silla,1998). Así, si el emperador tiene poder en la tierra, el poder de enviarlo a matar, Sebastián tendrá poder en el cielo por la gracia otorgada por Dios, y desde allí podrá afectar la acción de los hombres. 


\section{CONCLUSIONES}

Finalmente Vicente fue electo intendente y Lucía nuevamente concejal. Si bien fueron en la misma lista, Vicente siempre creyó que ella trabajó en su contra durante toda la campaña, apoyando a otros partidos, en especial el Partido Peronista.

Pero más allá del final de la historia, lo que me parece importante subrayar es la capacidad de Lucía de crear, relatar y reflexionar, en sólo media hora de duración, una serie de temáticas que posteriormente en mi trabajo de campo comprobé eran centrales para el análisis de la región: el pretendido origen chileno de la población (u ocultarse como chileno para no aparecer como mapuche), el tráfico transcordillerano, el impacto de los centros provinciales y nacionales en temas políticos y económicos, y el papel que ocupa el partido provincial como promotor del proceso de modernización y argentinización de la población.

Sabido es que la entrevista es una de las técnicas más apropiadas para acceder al universo de significación de los actores. Sabemos también que su inconveniente es que es fácil que ocurra que los supuestos del investigador se proyecten en el discurso, cerrando el acceso a nuevos e imprevistos sentidos. Por ello no debemos suponer que las preguntas formuladas por el investigador pertenecen al mismo universo de sentido que las respuestas del informante (Guber,1991:208), y tal vez por ello debí realizar mucho tiempo de trabajo de campo, muchas entrevistas y mucha participación en diferentes tipos de eventos en la región para poder darme cuenta de la importancia de esta primera entrevista.

Pero además, no sólo durante el momento de la entrevista, sino en el análisis mismo que estoy realizando de ella, casi diez años después de este encuentro, intenté seguir el relato tomando en cuenta todos los agentes que Lucía considera importantes para que todos los fenómenos arriba señalados ocurrieran. Así, todos los actores desplegados quedan asociados de tal modo que es evidente como uno hace hacer cosas al otro (Latour,2008:156). Para ello intenté seguir el fluir de las cosas, seguir a los actores y a lo que los hace actuar, los entes circulantes (Ibid. 333). En este seguimiento no quise diferenciar los agentes "reales" de las "metáforas", "representaciones" o "sublimaciones" que desde nuestra perspectiva académica consideraríamos crea o inventa Lucía. Preferí seguir su curso de razonamiento. Así, no hubiera sido concejal si no tuviera gente que la apoyara en la localidad y en el MPN. Pero según ella, tampoco hubiera sido concejal sin la ayuda de Dios, y Dios está en conexión con su capacidad de curar y con su devoción a San Sebastián. Lo mismo ocurrió con la creación y modernización del pueblo. La nacionalización y modernización, procesos que en la perspectiva local parecen ir juntos (todo avance en "las mejoras al pueblo" implican una mayor vinculación con los centros nacionales y provinciales) se realizó, según la concepción de Lucía, a partir de una serie de agentes de diversa índole y sustancia, humanos y no-humanos. Todos con algún tipo de poder para realizar esta gesta. Pero además no todos estos agentes provinieron de los centros políticos y económicos. El relato indica que muchas veces se ejecutaron agencias locales para traer a la nación, el Estado y su proceso modernizador, a la periferia.

$\mathrm{Al}$ describir los agentes que Lucía considera actuantes, describimos las teorías que posee sobre el mundo y la vida social. Mostramos cómo las personas en su actitud natural teorizan sobre el mundo y sus acontecimientos, y poseen métodos, etnométodos según Garfinkel (2006:20), para actuar en él. Lucía es entonces capaz de proponer sus propias teorías de la acción para explicar de qué modo se concretan los efectos de las acciones de los agentes, de cómo actúan y de dónde provienen sus fuerzas motoras.

Ahora bien, no podemos reducir el Dios o el San Sebastián de Lucía a relaciones sociales de las cuales ella no es conciente. Sabemos que la antropología, y en rigor todas las ciencias sociales, son ateas. No perdemos el tiempo arguyendo si Dios o los santos existen. Presumimos que son fabricaciones de la mente, de la imaginación individual o colectiva (Shweder,1989:116). Tampoco podemos decir que Dios o los santos son referentes empíricos. Sin embargo, si podemos rastrearlos, por ejemplo, en el relato que Lucía realiza de ellos, y a partir de ahí analizar sus consecuencias, pues para ella son reales, tienen poder y afectan su vida y las de los demás. En este sentido, Dios y San Sebastián son tan rastreables, tan reales o imaginarios, como sus descripciones de Felipe Sapag o la familia Urrutia. Lucía considera que el mundo está constituido por diferentes elementos, no todos humanos o pertenecientes al orden de lo natural, que no podemos decir que sean sublimaciones u oculten lo social, el poder político u económico. 
Lo que encontramos son asociaciones entre ella, los agentes humanos y los no-humanos. Entonces deberíamos definir a la sociedad como las consecuencias de estas asociaciones, no su causa (Latour,2008:334). Estas conexiones, realizadas por mediadores, hacen crear nuevos lazos y nuevas asociaciones. Cada uno es un agente que le hace hacer a los demás agentes cosas; o al menos creen, según sus propias teorías, que les hacen hacer cosas. Creo que así podríamos comenzar a intentar lo que Latour denominó una antropología simétrica ([1991]1997), o sea superar la diferencia entre los que creen (nuestros informantes) y los que saben (nosotros los investigadores), una forma de establecer un diálogo entre ambos, sin mutuamente suprimirnos.

\section{BIBLIOGRAFÍA}

ARIAS BUCCIARELLI, Mario. 1999. El Estado neuquino. Fortalezas y debilidades de una modalidad de intervención. En: Neuquén, la construcción de un orden estatal (Orietta Favaro ed.). Neuquén. Universidad Nacional del Comahue. Págs. 27-54.

BANDIERI, Susana. 1993. Actividades económicas y modalidades de asentamiento. En: Historia de Neuquén (Bandieri, Favaro, Morinelli comp.). Buenos Aires. Plus Ultra.

CARBAJAL, Lino. 1985 [1906]. Por el Alto Neuquén. Neuquén. Siringa Libros.

COULON, Alain. 1988. La etnometodología. Madrid. Ediciones Cátedra.

FRAPICCINI, Alina; Gabriel Rafart; Daniel Lvovich. 1995. Migración y fluctuaciones del mercado de trabajo: los trabajadores chilenos de Neuquén, 1884-1930. En: Estudios migratorios latinoamericanos, año 10, nำ30.

GARFINKEL, Harold. 2006 [1968]. Estudios en etnometodología. Barcelona. Editorial Anthropos.

GONZALEZ, Alicia; Maria Scuri. 1999. Partidos provinciales en un espacio provincial. Neuquén, 1957-1966. En: Neuquén, la construcción de un orden estatal (Orietta Favaro ed.). Neuquén. Universidad Nacional del Comahue. Págs. 81-106.

GUBER, Rosana. 1991. El salvaje metropolitano. Buenos Aires, Editorial Legasa.
HERITAGE, John. 1995 [1987]. Etnometodología. En La teoria social hoy; A. Giddens y J. Turner (compiladores). Buenos Aires. Editorial Alianza.

PALERMO, Vicente. 1988. Neuquén: la creación de una sociedad. Buenos Aires. Centro Editor de América Latina.

PITT-RIVERS, Julian y J. G. Peristany. 1993. Honor y gracia. Madrid. Editorial Alianza.

LATOUR, Bruno. 1997 [1991]. Jamais fomos modernos. Rio de Janeiro. Editora 34.

-2002 [1996]. Reflexão sobre o culto moderno dos deuses fe(i)tiches. Bauru. EDUSC.

-2008 [2005]. Reensamblar lo social. Una introducción a la teoría del actor-red. Buenos Aires. Editorial Manantial.

LEACH, Edmund. (1995) [1954]. Sistemas Políticos da Alta Birmania, São Paulo. Editorial Edusp.

LEVI-STRAUSS, Claude. 1997 [1958]. Antropología estructural. Barcelona. Ediciones Altaya.

MANARA, Carla. 2008. Un espacio fronterizo entre dos estados en expansión. En $3^{\circ}$ Jornadas de Historia de la Patagonia. San Carlos de Bariloche.

MILLER, Elmer. 1977. Simbolismo, conceptos de poder y cambio cultural de los tobas en el Chaco argentino. En: Procesos de articulación social, E. Hermitte y L. Bartolomé (compl.). Buenos Aires. Amorrortu editores. Págs 305-338.

SILLA, Rolando. 1998. La gracia de los débiles. El poder sobrenatural del soldado Carrasco como una concepción nativa de la justicia. En Revista de Investigaciones Folklóricas. Vol.13. Págs. 23-30. Buenos Aires.

-2003. Santos e Contrabandistas: a nacionalização de São Sebastião e a fronteira austral argentino-chilena. En: Mana. Estudos de antropologia social. Vol.9, №2. Págs.153-181. Ed. Contracapa. Rio de Janeiro.

-2006. La violencia de género en el Norte neuquino: el diagnóstico nativo. En Revista de investigaciones folclóricas, n²1. Págs. 165-192. Buenos Aires.

SHWEDER, Richard. 1989. Post-Nietzschian Anthropology: the idea of multiple objective worlds. En: Relativism. Interpretation and confrontation Michael Krausz (Ed.) Indiana University of Notre Dame Press.

VELHO, Otávio. 1995. Besta Fera. Recriação do mundo. Rio de Janeiro. Relume-Dumará. 
